\title{
Pilot Screening Study of the Angiogenesis Factor Pleiotrophin (PTN) in Serum Samples from Patients of Various Disease Groups
}

\author{
Gerhard Zugmaier $^{1}$, Athanasios Karalis ${ }^{1}$, Cornelius Knabbe ${ }^{2}$ and Achim Aigner ${ }^{3^{*}}$ \\ ${ }^{1}$ Department of Hematology, Oncology and Immunology, Philipps University of Marburg, and University Clinic Giessen and Marburg, Marburg, Germany \\ ${ }^{2}$ Institute for Laboratory and Transfusion Medicine, University Clinic of the Ruhr University Bochum \\ ${ }^{3}$ Rudolf-Boehm-Institute for Pharmacology and Toxicology, Clinical Pharmacology, Medical Faculty, Leipzig University, Germany
}

*Corresponding author: Achim Aigner, Rudolf-Boehm-Institute for Pharmacology and Toxicology, Clinical Pharmacology, Medical Faculty, Leipzig University, Germany, Tel: +49-(0)341-97-24661; E-mail: achim.aigner@medizin.uni-leipzig.de

Received date: March 26, 2018; Accepted date: April 10, 2018; Published date: April 24, 2018

Copyright: ( $) 2018$ Zugmaier G, et al. This is an open-access article distributed under the terms of the Creative Commons Attribution License, which permits unrestricted use, distribution, and reproduction in any medium, provided the original author and source are credited.

\begin{abstract}
Introduction: The secreted growth factor pleiotrophin (PTN) belongs to the midkine family of heparin-binding growth factors and is tightly regulated during embryogenesis. In contrast to its very limited expression in normal adult tissues, PTN protein levels are markedly increased in different tumors, with PTN showing mitogenic, chemotactic, transforming, pro-angiogenic, pro-invasive and pro-metastatic activity. However, little is known about PTN upregulation in diseases other than cancer. The aim of this study was to investigate PTN serum levels in patients with various non-malignant chronic or acute disorders, and in pregant women, compared to healthy nonpregnant blood donors as negative control group.
\end{abstract}

Materials and Methods: PTN serum levels were determined by a sandwich ELISA.

Results: PTN serum levels were found to be significantly elevated with a p-value of $<0.05$ in patients with the acute non-malignant disorders, acute inflammation, acute vascular disease and acute trauma. In patients with chronic leukemia and solid tumors, and pregnancy, increased PTN serum levels were detected as well.

Conclusion: Beyond its described functions in solid tumors and in the central nervous system, these data indicate that PTN is an acute phase protein in the adult organism and that, due to its upregulation under various non-cancer conditions, special caution must be taken when exploring PTN serum levels as potential tumor marker.

Keywords: Pleiotrophin; Acute and chronic disorders; Serum samples; ELISA; Inflammation; Vascular disease

\section{Introduction}

The secreted growth factor pleiotrophin (PTN), also called heparinbinding growth-associated molecule (HB-GAM), is a cytokine belonging to the midkine family of heparin-binding growth factors [1] PTN expression is tightly regulated during embryogenesis, with high expression in the developing nervous system, and shows very limited expression in normal adult tissues [2]. PTN is involved in the development and maintenance of the central nervous system [1-3], with protective effects upon its upregulation in neurodegenerative diseases and drug addiction [4], and in tissue regeneration [5]. In the hippocampus, PTN involvement in learning and memory has been shown [1-3]. Moreover, PTN shows mitogenic, chemotactic, transforming as well as pro-angiogenic, pro-invasive and prometastatic activity [6-9].

Concomitantly, a marked PTN upregulation on the mRNA and protein level was found in various human tumors and tumor cell lines [10-13]. For different tumors, increased PTN protein levels have also been demonstrated in patient serum and linked to tumor stage, thus suggesting a possible role as prognostic marker [14-19]. However, little is known about PTN upregulation in disorders other than malignant tumors, despite of its role in neurologic disorders (see above). This, however, will be important to determine (i) whether PTN may serve as putative target molecule in pathologies other than solid tumors, (ii) if a therapeutic PTN inhibition in cancer patients may lead to possible side effects, and (iii) if PTN (upregulation) may actually serve as biomarker for the early detection of tumors or for tumor progression, without being impaired by other effects that may lead to elevated PTN levels. Concomitantly, this study focused on the analysis of PTN levels in serum samples taken from patients with various non-malignant diseases.

\section{Materials and Methods}

In a municipal hospital, serum samples were collected within 2 consecutive days from 135 in or out patients with chronic or acute disorders, and from pregant women. In addition samples were collected from 4 patients treatment refractory with chronic leukemia (3 patients with chronic lymphatic and 1 with chronic myeloic leukemia) and 10 patients with treatment refractory solid tumors (2 patients with colon carcinoma, 2 with breast cancer, 2 with pancreatic cancer, 1 with ovary cancer, 1 with kidney cancer, 1 with prostate cancer and 1 with lung cancer) were collected. Details are given in Table 1. All blood draws had been done for medical reasons, independently from this study, and no additional blood samples were needed. Healthy non-pregnant blood donors served as normal control group. Appropriate institutional review board approval was obtained 
Page 2 of 3

prior to sample collection. The pleiotrophin ELISA was performed as described previously [15]. Briefly, a mouse anti-PTN monoclonal antibody (4B7) [19], diluted to $1 \mu \mathrm{g} / \mathrm{ml}$ in TBS (50 mM Tris- $\mathrm{HCl}, \mathrm{pH}$ $7.5,150 \mathrm{mM} \mathrm{NaCl}$ ), was used for coating 96-well ELISA plates at $4^{\circ} \mathrm{C}$ overnight. After washing with TBST (TBS+Tween-20), residual free binding sites were blocked for 1 hour at room temperature with $1 \%$ bovine serum albumin in TBST.

Serum samples were 1:1 diluted in 2X TBST and $100 \mu \mathrm{l} /$ well of this dilution was added and incubated at room temperature for 1 hour. After washing, $100 \mu \mathrm{l} /$ well biotinylated affinity-purified goat anti(human PTN) secondary antibody (R\&D, Wiesbaden, Germany) was added at a concentration of $500 \mathrm{ng} / \mathrm{ml}$ and incubated for 1 hour at room temperature. Following another washing step, the plate was incubated in the dark with $100 \mu \mathrm{l} /$ well p-nitrophenyl phosphate substrate solution for two hours. Absorbance was measured in an ELISA reader at $405 \mathrm{~nm}$. Recombinant human pleiotrophin (R\&D, Wiesbaden, Germany) served as the standard. The lower limit of detection under these assay conditions was determined at $1.5 \mathrm{ng} / \mathrm{ml}$ which is comparable to the literature [15]. ELISA results up to 30 $\mathrm{ng} / \mathrm{ml}$ were in the linear range, requiring appropriate dilution of samples when PTN levels were found to be higher. For statistical analysis, the Wilcoxon Rank-Sum Test and Student's t-Test were used. Differences in pleiotrophin serum levels with two sided p-values of $<0.05$ were considered as stastically significant, as done previously [19].

\begin{tabular}{|l|l|l|l|l|l|}
\hline \multicolumn{2}{|l|}{ Disease } & Number & $\begin{array}{l}\text { Mean } \\
\text { age }\end{array}$ & Male & Female \\
\hline \multirow{2}{*}{ Inflammation } & $\begin{array}{l}\text { Acute } \\
\text { inflammation }\end{array}$ & 19 & 60 & 9 & 10 \\
\cline { 2 - 7 } & $\begin{array}{l}\text { Chronic } \\
\text { inflammation }\end{array}$ & 11 & 62 & 8 & 3 \\
\hline \multirow{2}{*}{$\begin{array}{l}\text { Vascular } \\
\text { disease }\end{array}$} & $\begin{array}{l}\text { Acute vascular } \\
\text { disease }\end{array}$ & 23 & 69.5 & 13 & 10 \\
\cline { 2 - 7 } & $\begin{array}{l}\text { Chronic } \\
\text { vascular } \\
\text { disease }\end{array}$ & 54 & 71.5 & 29 & 25 \\
\hline Trauma & $\begin{array}{l}\text { Endocrine } \\
\text { diseases }\end{array}$ & 7 & 74 & 4 & 8 \\
\cline { 2 - 7 } & Pregnancy & 4 & 64 & 3 & 4 \\
\hline \multirow{2}{*}{ Other diagnoses } & Shock & 5 & 81 & 2 & 3 \\
\hline Total & 21 & 77 & 16 & 5 \\
\hline \multirow{2}{*}{ Negative control group } & 156 & 65.5 & 84 & 72 \\
\hline
\end{tabular}

Table 1: Overview of patients analyzed.

\section{Results and Discussion}

The mean PTN serum level in the normal control group was 2.63 $\mathrm{ng} / \mathrm{ml}$, with no value being above $5.00 \mathrm{ng} / \mathrm{ml}$. Thus, levels $\leq 5 \mathrm{ng} / \mathrm{ml}$ were defined as normal. Patients with chronic inflammation showed pleiotrophin serum levels within the normal range $(<5 \mathrm{ng} / \mathrm{ml})$. In contrast, highly elevated PTN serum levels were observed in patients with acute disorders, in particular acute inflammation prior to therapy, soft tissue trauma and burn, and acute cardiovascular disease (Table 2 and Figure 1).

\begin{tabular}{|l|l|l|}
\hline & Median pleiotrophin levels & P value \\
\hline Acute inflammation & 24.9 & $\leq 0.05$ \\
\hline Trauma & 14.9 & $\leq 0.05$ \\
\hline Acute vascular disease & 13.3 & $\leq 0.05$ \\
\hline Pregnancy & 15.6 & n.s. \\
\hline Endocrine diseases & 10.9 & n.s. \\
\hline Shock & 4.6 & n.s. \\
\hline n.s. = non significant & & \\
\hline
\end{tabular}

Table 2: PTN serum levels in patients.

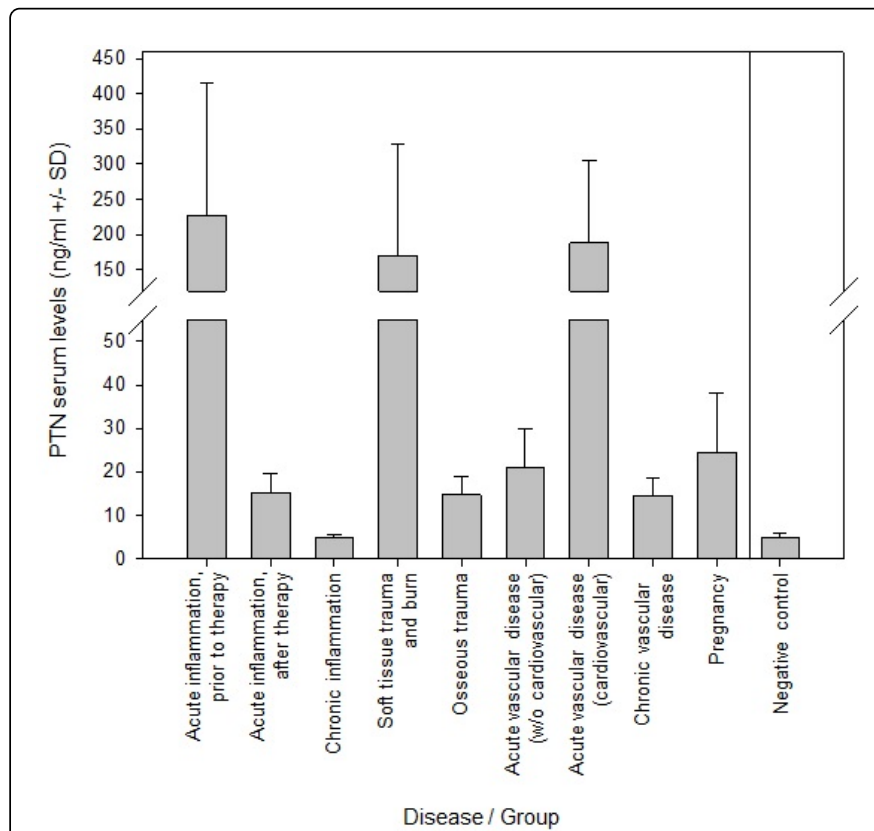

Figure 1: PTN serum levels in patients of various disease groups, as determined by ELISA.

For acute inflammation, serum samples were availabe from patients without treatment as well as from treated patients. One patient without treatment was diagnosed with erysipel, four with acute gastrointestinal disorders and one with acute pneumonia. The mean pleiotrophin level in serum was $228 \mathrm{ng} / \mathrm{ml}$, which was $\sim 50$-fold higher than in normal serum and $>10$-fold higher than in patients with acute inflammation after treatment $(15 \mathrm{ng} / \mathrm{ml})$. In the latter group, eight patients had been diagnosed with acute gastro-intestinal disorders and seven with pneumonia. From patients with trauma or acute vascular disorder, blood samples had been obtained within 2 days after the invasive treatment procedure. Three patients had been diagnosed with abdominal trauma and one with burns. These four patients were categorized as patients with soft tissue trauma, with their mean PTN serum level being $>30$-fold increased $(170 \mathrm{ng} / \mathrm{ml})$. In contrast, in the eight patients with bone traumas, PTN was only $\sim 3$-fold above normal (15 ng/ml). Acute vascular disorders were categorized as acute cardiovascular disorders and other acute vascular disorders. In the sixteen patients diagnosed with acute cardiovascular disorders, a very 
high mean PTN serum level of $188 \mathrm{ng} / \mathrm{ml}$ was determined, while the seven patients with other acute vascular disorders showed only a moderate increase $(21 \mathrm{ng} / \mathrm{ml})$. Similar levels were also observed in chronic vascular disease $(14.6 \mathrm{ng} / \mathrm{ml})$ and in pregnant women $(24.5$ $\mathrm{ng} / \mathrm{ml})$.

Although the study was focused on non-malignant disorders serum samples were also collected from patients with treatment-refractory malignant disorders, who were at the hospital during the 2 days in which serum samples were collected. The median PTN level was 21.6 in patients with chronic leukemia and 14.52 in patients with solid tumors. The difference to the controls was statistically not significant.

This study was set to determine PTN serum levels in patients with non-malignant disorders and settings, including inflammation, trauma, vascular disorders and pregnancy. The highest PTN levels with mean serum concentrations $>30-50$ fold above normal were found in acute inflammation, acute ischemia and acute soft tissue trauma. These data indicate that highly elevated PTN levels are not restricted to malignant tumors but can also be found in non-malignant conditions. This is consistent with published data on the role of PTN in non-tumor settings. While in non-malignant processes PTN can exhibit a mechanism of action similar to that in cancer, such as induction of cell growth and angiogenesis in wound healing and bone repair [20,21], other functions have been identified as well in inflammation. It has been shown that PTN induces the expression of inflammatory cytokines in human peripheral blood mononuclear cells [22]. Given the PTN elevation under various inflammatory conditions or even during pregnancy, special caution must be taken when exploring or employing PTN serum levels as tumor marker.

\section{Conclusion}

Our data show that, apart from cancer, pleiotrophin levels are markedly increased in various acute non-malignant disorders that are e.g. related to inflammation. While this supports the role of PTN as acute phase protein beyond its functions as growth and angiogenesis factor in tumors, it also identifies profound caveats towards using PTN serum levels as biomarker for tumor detection and progression. Larger studies are warranted, in order to investigate the role of pleiotrophin in different non-malignant diseases and to investigate the courses of pleiotrophin serum levels from baseline to completion of treatment.

\section{Acknowledgements}

The authors are grateful to Helga Radler for expert technical assistance. The authors declare no potential conflicts of interest relevant to this article.

\section{References}

1. Castillo CG, Sahagun DO, Brambila CG, Pallas M, Mayorquin AER (2014) Pleiotrophin as a central nervous system neuromodulator, evidences from the hippocampus. Front. Cellular Neurosci 8: 443.

2. Winkler C, Yao S (2014) The midkine family of growth factors: diverse roles in nervous system formation and maintenance. Br J Pharmacol 171: 905-912.

3. Kuboyama K, Fujikawa A, Suzuki R, Noda M (2015) Inactivation of Protein Tyrosine Phosphatase Receptor Type Z by Pleiotrophin Promotes Remyelination through Activation of Differentiation of Oligodendrocyte Precursor Cells. J Neurosci 35: 12162-12171.
4. Alguacil LF, Herradon G (2015) Midkine and Pleiotrophin in the Treatment of Neurodegenerative Diseases and Drug Addiction. Rec Pat CNS Drug Disc 10: 28-33.

5. Xu C, Zhu S, Wu M, Han W, Yu Y (2014) Functional receptors and intracellular signal pathways of midkine (MK) and pleiotrophin (PTN). Biol Pharmaceutical Bull 37: 511-520.

6. Czubayko F, Riegel AT, Wellstein A (1994) Ribozyme-targeting elucidates a direct role of pleiotrophin in tumor growth. J Biol Chem 269: 21358-21363.

7. Czubayko F, Schulte AM, Berchem GJ, Wellstein A (1996) Melanoma angiogenesis and metastasis modulated by ribozyme targeting of the secreted growth factor pleiotrophin. Proc Natl Acad Sci USA 93: 14753-14758.

8. Papadimitriou E, Mikelis C, Lampropoulou E, Koutsioumpa M, Theochari K, et al. (2009) Roles of pleiotrophin in tumor growth and angiogenesis. Eur Cytokine Network 20: 180-190.

9. Elahouel R, Blanc C, Carpentier G, Frechault S, Cascone I, et al. (2015) Pleiotrophin exerts its migration and invasion effect through the neuropilin-1 pathway. Neoplasia 17: 613-624.

10. Zhang N, Zhong R, Wang ZY, Deuel TF (1997) Human breast cancer growth inhibited in vivo by a dominant negative pleiotrophin mutant. J Biol Chem 272: 16733-16736.

11. Jager R, Noll K, Havemann K, Pflüger KH, Knabbe C, et al. (1997) Differential expression and biological activity of the heparin-binding growth-associated molecule (HB-GAM) in lung cancer cell lines. Int J Cancer 73: 537-543.

12. Jee YH, Sadowski SM, Celi FS, Xi L, Raffeld M, et al. (2016) Increased Pleiotrophin Concentrations in Papillary Thyroid Cancer. PloS one 11: e0149383.

13. Zhang L, Kundu S, Feenstra T, Li X, Jin C, et al. (2015) Pleiotrophin promotes vascular abnormalization in gliomas and correlates with poor survival in patients with astrocytomas. Science Signaling 8: ra125.

14. Klomp HJ, Zernial O, Flachmann S, Wellstein A, Juhl H (2002) Significance of the expression of the growth factor pleiotrophin in pancreatic cancer patients. Clin Cancer Res 8: 823-827.

15. Aigner A, Brachmann P, Beyer J, Jäger R, Raulais D, et al. (2003) Marked increase of the growth factors pleiotrophin and fibroblast growth factor-2 in serum of testicular cancer patients. Ann Oncol 14: 1525-1529.

16. Jager R, List, Knabbe C, Souttou B, Raulais D, et al. (2002) Serum levels of the angiogenic factor pleiotrophin in relation to disease stage in lung cancer patients. Br J Cancer 86: 858-863.

17. Hu H, Li C, Cai S, Zhu C, Tian Y, et al. (2014) Increased expression of pleiotrophin is a prognostic marker for patients with gastric cancer. Hepato-gastroenterology 61: 1478-1482.

18. Du ZY, Shi MH, Ji CH, Yu Y (2015) Serum pleiotrophin could be an early indicator for diagnosis and prognosis of non-small cell lung cancer. Asian Pacific J Cancer Prevention: APJCP 16: 1421-1425.

19. Souttou B, Juhl H, Hackenbruck J, Röckseisen M, Klomp HJ, et al. (1998) Relationship between serum concentrations of the growth factor pleiotrophin and pleiotrophin-positive tumors. J Natl Cancer Inst 90: 1468-1473.

20. Lamprou M, Kaspiris A, Panagiotopoulos E, Giannoudis PV, Papadimitriou E (2014) The role of pleiotrophin in bone repair. Injury 45: 1816-1823.

21. Deuel TF, Zhang N, Yeh HJ, Santiago IS, Wang ZY (2002) Pleiotrophin: a cytokine with diverse functions and a novel signaling pathway. Arch Biochem Biophys 397: 162-171.

22. Achoura A, M'Bikaa JP, Baudouin F, Caruelle D, Courty J (2008) Pleiotrophin induces expression of inflammatory cytokines in peripheral blood mononuclear cells. Biochimie 90: 1791-1795. 